\title{
EVALUATION OF TANKER VEHICLE SELECTION USING A NOVEL HYBRID FUZZY MCDM TECHNIQUE
}

\author{
Omer Faruk Görçün¹, S. Senthil², and Hande Küçükönder 3* \\ ${ }^{1}$ Faculty of Business, Department of Business Management, Kadir Has University, \\ Istanbul, Turkey \\ 2 Department of Mechanical Engineering, Kamaraj College of Engineering and \\ Technology, Virudhunagar, India \\ ${ }^{3}$ Department of Business Administration, Faculty of Economics and Administrative \\ Sciences, Bartin University, Bartın, Turkey
}

Received: 26 April 2021;

Accepted: 28 May 2021;

Available online: 13 June 2021.

Original scientific paper Abstract: Petroleum products transportation considered as one of the crucial parts of dangerous material transportation is a risky logistics activity. The selection of the appropriate tanker vehicles may be a suitable solution to reduce the risks and increase the efficiency and performance of the fuel transportation companies. However, the selection of a suitable road tanker vehicle is not an easy task for decision-makers as there are many conflicting criteria and many decision alternatives. In addition, decision-makers may have to decide with insufficient information since collecting crisp values may not be possible at all times. Hence, many ambiguities affecting the evaluation results exist in an assessment process performed to select the best tanker vehicle option. This paper suggests a novel integrated fuzzy approach to solve these decision-making problems. Sensitivity analysis is conducted to test the validation of the proposed integrated fuzzy approach and its results was performed by forming 130 scenarios. The results of sensitivity analysis prove that the proposed model can be applied to solve these kinds of decisionmaking problems.

Key words: Road tanker vehicle, Fuzzy SWARA, Fuzzy CODAS, dangerous goods transportation, MCDM.

\section{Introduction}

In recent years, the flammable liquid transportation industry is an important part of the dangerous goods logistics industry has grown quickly depending on the increase of energy needs of both industries and individuals. The number of car

* Corresponding author.

E-mail addresses: omer.gorcun@khas.edu.tr (O.F. Gorcun), itssenthil@yahoo.com (S. Senthil), hkucukonder@bartin.edu.tr (H. Küçükönder) 


\section{Evaluation of tanker vehicle selection using a novel hybrid fuzzy MCDM technique}

ownership per 1000 inhabitants has averagely increased at the rate of $17.61 \%$ around the world between 2001 and 2020 (OECD 2021). Increase in car ownership has caused to increase energy needs of individuals. Hence, the volume of fuel transported has shown a sharp increase in both urban and rural areas. The reports published by market insight companies and international institutions suggest that this trend will continue increasingly in near future and the analysts forecast that the global oil transportation market will grow at the rate of $7.00 \%$ annually. The risks associated with the transport activities will also increase.

Selection of the most appropriate tanker vehicle is a very crucial task for decisionmakers with respect to reducing the risks in addition to the efficiency and performance of the oil and petroleum products transportation. However, there is no study on the selection of proper road tanker vehicles in the literature, even though dangerous goods transportation is a very important issue for all parties of logistics such as international and national policymakers, operators, companies, local authorities, and ordinary citizens.

Previous work on dangerous goods transportation focused on route selection (Bęczkowska, 2019; Wang \& Liang, 2020; Li, 2018). A multi-objective mathematical model is used for selection of dangerous goods transportation (Samanlığlu, 2013; Pamučar et al. 2016; Jassbi \& Makvandi, 2010). Also, many studies are available on dangerous materials transportation such as designing the terminal layout for safety (Santarremigia et al., 2018; Hervás-Peralta, 2020), evaluating safety systems in airfreight operations (Huang et al., 2020), risk assessment (Huang et al., 2021; Kanj et al., 2019; Galieriková et al., 2018; Gul et al., 2019; Raemdonck et al., 2013), evaluation of the work of advisors in the transport of hazardous goods (Pamucar et al., 2019; Milosevic et al., 2021). A limited study is carried on the selection of freight trailers (Görçün, 2019a; Görçün, 2019b) but they are not related to tanker selection. Equipment and vehicles used in ordinary freight transportation are quite different from equipment and vehicles used in dangerous goods transportation. Hence it is not possible to connect between previous works dealing with freight trailer selection and the current paper focuses on the road tanker selection.

To the best of our knowledge, there is no study dealing with the selection of transport vehicle. The selection of the appropriate road tanker vehicle has vital importance and is crucial for companies, governments, local authorities, and individuals. It can also be a determinative factor for effectivity and performance of a HAZMAT (Hazardous Materials) transport company.

To analyze the significant criteria affecting the selection of proper tanker vehicles, a set of research questions were determined. A team of experts is formed. All of them are also experts and advisors of hazardous materials transportation certificated by public authority. The researchers organized many face-to-face interviews with each expert and directed these research questions to the experts. At the end of the face-toface interviews, preparing a list for decision alternatives and criteria was requested from each professional. These lists were collected and researchers eliminated the repetitive criteria and the final list for criteria and options has been determined by providing full consensus among these experts. Hence, the determined selection criteria are realistic and suitable to real-life and they can also be used by future works and it can be taken into consideration by practitioners in a reel assessment process.

As another finding of the research process, experts indicate that there is no mathematical model implemented to determine the best tanker vehicle in the field of hazardous materials transportation, furthermore, decision-makers, who responsible 
to decide on this issue, make decision based on their own experiences, and they mostly consider each process as a case. It proves that using a mathematical model is a crucial requirement for solving these kinds of decision-making problems encountered in the field of dangerous goods transportation. In order to respond to these requirements, the current paper proposes an integrated fuzzy approach consisting of the fuzzy Step-Wise Weight Assessment Ratio Analysis (F-SWARA) and the combinative Distance-based assessment (F-CODAS) techniques.

Although the fuzzy CODAS technique that is a part of the proposed integrated fuzzy model is a novel multi-criteria decision-making (MCDM) approach, it has been observed that it has been applied in some studies for solving decision-making problems in various fields. For example; evaluation of IT technology alternatives for a university (Dahooie et al., 2020), evaluation of environmental quality (Ouhibi \& Frikha, 2020), the selection of vehicle shredding facility location (Simic et al., 2021), evaluation of renewable energy alternatives (Deveci et. al., 2020), evaluation of personnel selection problem (Yalçın \& Pehlivan, 2019), market segment evaluation (Keshavarz Ghorabaee et al., 2016a). The number of studies using the F-CODAS technique is very limited and none of these papers dealt with decision-making problems encountered in the field of logistics.

The classical decision-making techniques use crisp values to assess the options however these evaluations are not working and they often fail in real life. There are many uncertainties in an assessment process and decision-makers may have to make decisions with insufficient information (Pamucar \& Savin, 2020). The proposed integrated fuzzy approach can enable to deal with ambiguities because it has the ability to include the ambiguities to the scope of the evaluation process. In addition, this technique takes into consideration the combinative form of Euclidean distance and Hamming distance in the aspect of the intangibility of decision-maker (DM). Hence it can present accurate and reasonable results by considering ambiguities (Wang et al., 2020; Ali et al., 2021). The proposed method can be used as a methodological frame for both future works and practitioners who responsible to decide in the field of dangerous goods logistics.

After the proposed integrated fuzzy approach was applied, a comprehensive sensitivity analysis consisting of two stages was performed to test the validation of the model and its results by forming different 130 scenarios. According to the results of the analysis, A5 has remained for all scenarios and its ranking performance has never changed. In addition, it has been observed minor changes, which did not change the overall results, in the ranking performances of some alternatives. The results of the analysis prove that, the proposed fuzzy model is a very strong approach and its ranking results are reasonable, accurate and realistic. Hence, it can be applied to solve these kinds of decision-making problems encountered in various fields of logistics in addition to the dangerous goods logistics industry. The major contribution of this work is:

- It presents a set of criteria, which are novel and suitable to real life, for evaluating the road tanker vehicle selection. There is no criterion defined by previous studies in this field.

- The proposed integrated fuzzy approach is a novel MCDM technique and it can contribute to future work that will be carried out on this issue as well as it can help to practitioners in the field of hazardous material transportation.

- It presents a methodological frame which can enable to deal with many ambiguities existing in an assessment process on the tanker vehicle selection. 
The rest of the paper is organized as follows. In section 2, the proposed integrated fuzzy approach consisting of F-SWARA and F-CODAS and its basic algorithm consisting of four stages are presented. Section 3 describes the numerical analysis for calculating the selection criteria and determines the ranking performances of the road tanker vehicle alternatives. In section 4 , a comprehensive sensitivity analysis is performed to test the validation of the proposed integrated fuzzy model and its results. Section 5 describes the overall results and conclusions. The limitations encountered during the research process, and a set of suggestions for future works are presented.

\section{The Proposed Integrated Fuzzy Approach}

The proposed integrated fuzzy approach and its basic algorithm are presented in this section. The proposed model consists of three stages. The first stage is organized as the preparation process. The main problems were determined, the board of experts was formed, after the criteria and decision alternatives were defined fuzzy data were collected in this phase. The weights of the criteria were computed by applying the F-SWARA technique. Finally, the ranking performances of the decision alternatives were determined by using the F-CODAS technique. The basic algorithm of the proposed model is presented in Figure 1.
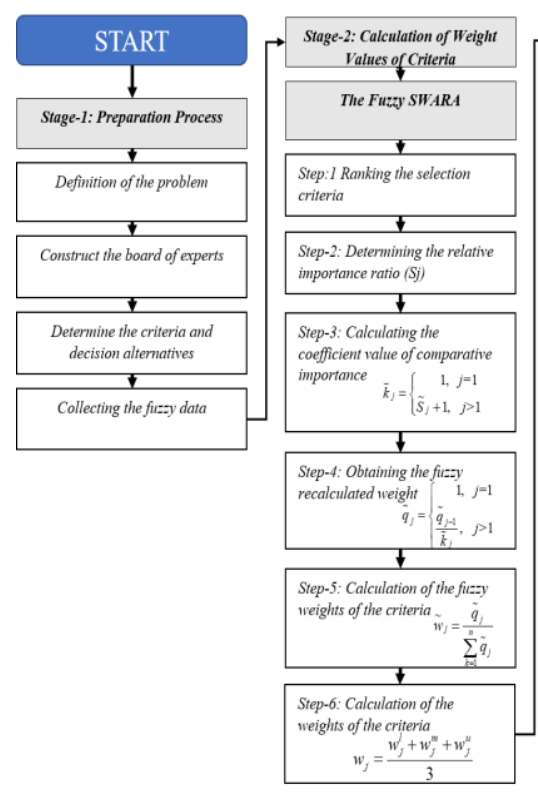

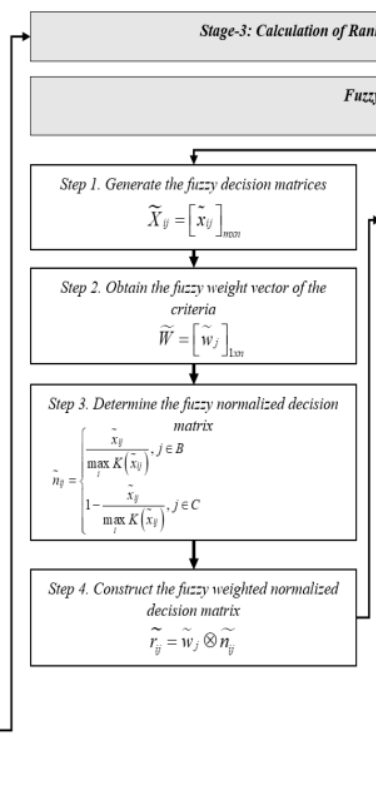

CODAS

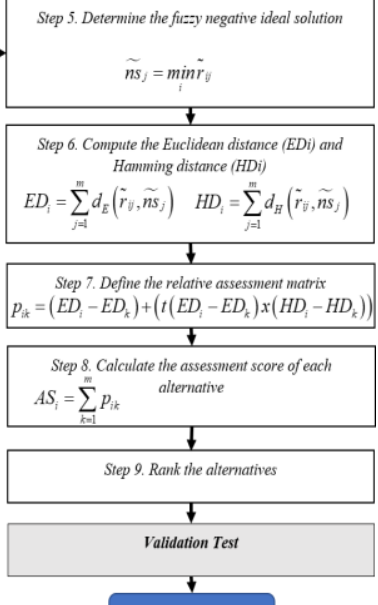

END

Figure 1. The basic algorithm of the proposed integrated fuzzy model

\subsection{Preliminaries}

The fuzzy set theory introduced by Zadeh (1965) is a useful technique enabling to deal with ambiguities for decision-makers. The fuzzy sets have degrees of membership and the fuzzy set theory uses triangular fuzzy numbers (TFNs) to convert the linguistic evaluations. 
A fuzzy number $\tilde{A}$ on $\mathrm{R}$ to be an FTN if its membership function $\mu_{\tilde{A}}(x): \mathrm{R} \rightarrow[0,1]$ is equal to the following equation (1) (Zadeh, 1965):

$$
\mu_{\tilde{A}}(x)= \begin{cases}\frac{x-l}{m-l} & l \leq x \leq m \\ \frac{u-x}{u-m} & m \leq x \leq u \\ 0 & \text { otherwise }\end{cases}
$$

As is seen from equation 1 , the values of $l, m$, and $u$ symbolize TFNs and while $l$ is the minimum value, $u$ denotes the maximum value of the fuzzy number, and $m$ represents the moderate value of the fuzzy number. the fuzzy set theory has been used by many studies (Petrovic et al., 2019; Deveci et al., 2020; Pamucar \& Ecer, 2020; Ecer \& Pamucar, 2020; Alosta et al., 2021).

\subsection{The fuzzy SWARA Technique}

The fuzzy SWARA (F-SWARA) technique is an extended version of the traditional SWARA technique developed by Kersuliene et al. (2010). This technique is preferred over other traditional MCDM techniques such as AHP and ANP.

This can estimate the decision makers preferences considering the significances of the criteria (Mardani et al., 2017). It does not require an additional consistency analysis as this fuzzy technique is maximally consistent. The basic algorithm of the fuzzy SWARA technique consisting of five implementation steps is given below: (Mavi et al., 2017; Perçin 2019; Sumrit et. al., 2012; Zolfani \& Saparauskas 2013).

Step 1. Rank the selection criteria: In a group decision process, each expert ranks the criteria. Next, the ranking position of each criterion is determined by computing the arithmetic mean of given ranking scores by experts.

Step 2. Determine the relative importance ratio: After the criteria are ranked, the criterion is compared with the next criterion by each expert. The criterion $j$ is compared with the criterion of $j-1$. To make these comparisons, decision-makers use the linguistic terms given in the linguistic evaluation scale which is given in Table 4. These evaluations are converted to the corresponding triangular fuzzy numbers (TFNs) in the evaluation scale. By calculating the arithmetic mean of these values, the final fuzzy relative importance ratio of each criterion is determined.

Step 3. Calculate the coefficient $k_{j}$ as Eq. (2):

$k_{j}=\left\{\begin{array}{l}\tilde{1}_{1}, \quad j=1 \\ \tilde{s}_{j}+1, \quad j>1\end{array}\right.$

Step 4. Compute the intermediated weight $q_{j}$ as Eq. (3):

$q_{j}= \begin{cases}\tilde{1}, & j=1 \\ \frac{q_{j-1}}{k_{j}}, & j>1\end{cases}$

Where; $q_{j}=\left(q_{j}^{l}, q_{j}^{m}, q_{j}^{u}\right)$ 
Step 5. Compute the relative weights of the evaluation criteria as Eq. (4):

$$
w_{j}=\frac{q_{j}}{\sum_{k=1}^{n} q_{j}}
$$

Where $w_{j}$ donates the fuzzy weight of criterion $\mathbf{j}$.

Step 6. Compute non-fuzzy value of $w_{j}$ as Eq. (5):

$$
w_{j}=\frac{\left(w_{j}^{l}+w_{j}^{m}+w_{j}^{u}\right)}{3}
$$

\subsection{The fuzzy CODAS Technique}

The combinative distance-based assessment (CODAS) technique developed by Keshavarz Ghorabaee et al. (2016) is a quite novel MCDM technique and is a very useful approach. This technique considers a combinative form of the Euclidean distance and Taxicab distance to determine the ranking performances of the decision alternatives. However, the CODAS technique gives results when crisp values are available. In order to present an MCDM technique, which enables to deal with uncertainties, this approach was extended in later studies (Keshavarz Ghorabaee et al., 2016a; Yalçın \& Pehlivan, 2019; Vinodh \& Wankhede, 2020; Roy et. al., 2019) with the help of the fuzzy set theory introduced by Zadeh (1965). The basic algorithm of the fuzzy CODAS (F-CODAS) technique consisting of nine implementation steps are given as follows: (Keshavarz Ghorabaee et al., 2016a; Yalçın \& Pehlivan, 2019; Roy et. al., 2019; Katrancı \& Kundakcl, 2020)

Step 1. Generate the fuzzy decision matrix: In a group decision process, $k$ number of experts evaluate $m$ number of decision alternatives by considering $n$ number of criteria as seen in equation 6 . The decision-makers perform linguistic evaluations for options considering the linguistic terms given in Table 5.

$$
X^{1}=\left[\begin{array}{cccc}
x_{11}^{1} & x_{12}^{1} & \ldots & x_{1 n}^{1} \\
x_{21}^{1} & x_{22}^{1} & \ldots & x_{2 n}^{1} \\
x_{31}^{1} & x_{32}^{1} & \cdots & x_{3 n}^{1} \\
x_{m 1}^{1} & x_{m 2}^{1} & \cdots & x_{m n}^{1}
\end{array}\right], X^{2}=\left[\begin{array}{cccc}
x_{11}^{2} & x_{12}^{2} & \ldots & x_{1 n}^{2} \\
x_{21}^{2} & x_{22}^{2} & \ldots & x_{2 n}^{2} \\
x_{31}^{2} & x_{32}^{2} & \cdots & x_{3 n}^{2} \\
x_{m 1}^{2} & x_{m 2}^{2} & \cdots & x_{m n}^{2}
\end{array}\right], \ldots, X^{k}=\left[\begin{array}{cccc}
x_{11}^{k} & x_{12}^{k} & \ldots & x_{1 n}^{k} \\
x_{21}^{k} & x_{22}^{k} & \cdots & x_{2 n}^{k} \\
x_{31}^{k} & x_{32}^{k} & \cdots & x_{3 n}^{k} \\
x_{m 1}^{k} & x_{m 2}^{k} & \cdots & x_{m n}^{k}
\end{array}\right]
$$

Next, these evaluations are converted to the corresponding TFNs in the linguistic evaluation scale. As a result, the $\mathrm{k}$ numbers of initial fuzzy decision matrices are obtained. Finally, these matrices are combined and the initial aggregated fuzzy matrix is formed as follows (equation 7). 


$$
X=\left[\begin{array}{cccc}
x_{11} & x_{12} & \ldots & x_{1 n} \\
x_{21} & x_{22} & \ldots & x_{2 n} \\
\cdots & \cdots & \cdots & \cdots \\
x_{m 1} & x_{m 2} & \cdots & x_{m n}
\end{array}\right]
$$

Where the element of the matrix $x_{i j}$ denotes the average fuzzy rating score of $i^{\text {th }}$ option with respect to $j^{\text {th }}$ criterion and $k$ symbolizes the number of experts.

Step 2. Determine the weights of criteria: The fuzzy weight of each criterion is determined in the previous stage of the suggested integrated fuzzy approach with the help of the F-SWARA technique.

Step 3. Generate the fuzzy normalized decision matrix: The fuzzy aggregated matrix is normalized by applying equation 8 .

$$
n_{i j}=\left\{\begin{array}{l}
\frac{x_{i j}}{\max _{i} K\left(x_{i j}\right)}, \quad j \in B \\
1-\frac{x_{i j}}{\max _{i} K\left(x_{i j}\right)}, j \in C
\end{array}\right.
$$

$B$ denotes the benefit criteria; $C$ symbolizes the cost criteria.

Step 4. Form the fuzzy weighted normalized decision matrix: The fuzzy normalized matrix $N=\left[n_{i j}\right]_{m x n}$ is weighted by using equation 9 and the weighted normalized fuzzy matrix $R=\left[\tilde{r}_{i j}\right]_{m x n}$ is constructed.

$$
\tilde{r}_{i j}=n_{i j} \otimes w_{j}
$$

Step 5. Determine fuzzy negative-ideal solution as Eqs. (10-11)

$$
\begin{gathered}
N S=\left[n s_{j}\right]_{1 x m} \\
n s_{j}=\min _{i} \tilde{r}_{i j}
\end{gathered}
$$

Where $\min _{i} \tilde{r}_{i j}=\left\{\tilde{r}_{k j} \mid \kappa\left(\tilde{r}_{k j}\right)=\min _{i}\left(\kappa\left(\tilde{r}_{k j}\right)\right), \mathrm{k}=1,2, \ldots \mathrm{n}\right\}$

Step 6. Calculate the Euclidean distance $\left(E D_{i}\right)$ and Hamming distance $\left(H D_{i}\right)$ : The distance values for each alternative are computed by using equations 12 and 13 .

$$
\begin{aligned}
E D_{i} & =\sum_{j=1}^{m} d_{E}\left(\tilde{r}_{i j}, n s_{j}\right) \\
H D_{i} & =\sum_{j=1}^{m} d_{H}\left(\tilde{r}_{i j}, n s_{j}\right)
\end{aligned}
$$

Step 7. Determine relative assessment matrix $R A=\left[p_{i k}\right]_{m x n}$ Eq. (14): 
Evaluation of tanker vehicle selection using a novel hybrid fuzzy MCDM technique

$p_{i k}=\left(E D_{i}-E D_{k}\right)+\left(t\left(E D_{i}-E D_{k}\right) x\left(H D_{i}-H D_{k}\right)\right)$

$t(x)= \begin{cases}1 & \text { if }|x| \geq \theta \\ 0 & \text { if }|x|<\theta\end{cases}$

The threshold parameter $(\theta)$ of this function can be set by decision-maker. It can take values between 0 and 1 .

Step 8. Compute the assessment score $\left(A S_{i}\right)$ of each alternative by using equation 16.

$$
A S_{i}=\sum_{k=1}^{m} p_{i k}
$$

Step 9. Rank the decision alternatives: Decision alternatives are ranked with respect to their assessment scores in descended order. The best alternative is determined as the option having the highest assessment score.

\section{Evaluation of the road tanker vehicle alternatives}

In this section, the proposed integrated fuzzy approach is implemented to solve the decision-making problems related to the selection of road tanker vehicles. By following the basic algorithm of the integrated fuzzy model, the best solution was tried to obtain.

Details of the selected professionals are given in Table 1.

Table 1. Details of the Members of the Board of Experts

\begin{tabular}{cllcl}
\hline No & Graduate & Duty & Exp. & Country \\
\hline DM-1 & Logistics Management & Advisor of DG & 14 & Turkey \\
DM-2 & Business Management & Advisor of DG & 18 & Turkey \\
DM-3 & Logistics Management & Advisor of DG & 17 & Netherlands \\
DM-4 & Business Management & Advisor of DG & 18 & Turkey \\
DM-5 & Mechanical Engineering & Advisor of DG & 21 & Bulgaria \\
DM-6 & Industrial Engineering & Advisor of DG & 27 & India \\
\hline
\end{tabular}

The research questions determined in the first step of the research process were directed to these experts and the obtained answers were recorded. As one of the most significant findings of these research process, it has been ascertained that there is no mathematical model or computational tool used for solving the road tanker selection problem. According to the opinions of the members of the board of experts, decisionmakers mostly decide considering their own experiences and, knowledge, and competence furthermore they consider these kinds of problems as singly case.

At the end of the face-to-face interviews and well-attended meetings with the members of the boards, researchers requested to prepare a list from each expert to determine the selection criteria. Next, these lists were combined and the final criteria list was formed as in the Table 2 . 
Görçün et al./Decis. Mak. Appl. Manag. Eng. 4 (2) (2021) 140-162

Table 2. The selection criteria for road tanker vehicles

\begin{tabular}{clcl}
\hline Code & Criteria & Code & Criteria \\
\hline $\mathrm{C}_{1}$ & Purchase Price & $\mathrm{C}_{8}$ & Empty weight \\
$\mathrm{C}_{2}$ & Maintenance Cost & $\mathrm{C}_{9}$ & Tanker Length \\
$\mathrm{C}_{3}$ & Number of Authorized Services & $\mathrm{C}_{10}$ & Number of divisions \\
$\mathrm{C}_{4}$ & Capacity & $\mathrm{C}_{11}$ & Design Pressure Value \\
$\mathrm{C}_{5}$ & Material thickness & $\mathrm{C}_{12}$ & Design Temperature Value Max \\
$\mathrm{C}_{6}$ & Safety & $\mathrm{C}_{13}$ & Design Temperature Value Min \\
$\mathrm{C}_{7}$ & Loaded weight & & \\
\hline
\end{tabular}

According to the opinions of the experts, technical and economic criteria are crucial to select the appropriate road tanker vehicle. these vehicles should be in good condition and they have to respond some requirements related to dangerous goods transportation. As a result of negotiations taken long time with the experts, the selection criteria were determined by providing full consensus among these experts. the set of the selection criteria are defined as follows:

C1 Purchase Price: it is the price an individual or companies, which operates dangerous goods transportation, pays for purchasing a road tanker vehicle. It can also be defined as the acquisition cost.

C2 Maintenance Cost: it refers to the expense incurred to ensure that a road tanker vehicle continues to operate healthily. the maintenance cost is also defined as all kinds of costs which are bear by individuals or businesses for keeping their vehicles in good working condition.

C3 Number of Authorized Services: It refers to the number of authorized service suppliers, which can provide for regular or irregular maintaining and repairing support at the global level.

C4 Capacity: it refers to the total weight capacity that can be carried by a road tanker vehicle at a minimum or zero risk level in terms of the liter, $\mathrm{m} 3$, or tons.

C5 Material thickness: it defines the thickness of materials used for manufacturing a road tanker. UNECE has determined minimum standards on metal plate thickness used as a semi-finished product for manufacturers and transport operators since it is very crucial for safety and security.

C6 Safety: it refers to the availability of the safety requirements, which determined by international institutions on dangerous transportation, for a road tanker vehicle. all of them may not be installed on each road tanker or all of the safety equipment such as electronic stability control systems, safety valves, manholes, Internal bulkheads, and so on may not have the same quality and abilities. due to these differences, the safety level of a road tanker is one of the crucial factors for selecting the appropriate vehicle.

C7 Loaded weight: it means to total weight of the loaded tanker vehicle. it equals the sum of the weight of liquid cargo and tare weight of a vehicle. overweighting can cause to rollover of road tanker vehicles as there is a negative correlation between the total weight and vehicle stability. Hence, it is a crucial factor that affects road, vehicle, and cargo security directly.

C8 Empty weight: Empty weight means the weight of a road tanker vehicle including the operating body and accessories. there is a negative correlation between the empty weight of a tanker vehicle and its carrying capacity. Hence, it can be accepted as both a technical and economic criterion since it is a determinative factor with respect to the carriage capacity of a vehicle. 
Evaluation of tanker vehicle selection using a novel hybrid fuzzy MCDM technique

C9 Tanker Length: it refers to the maximum length of a road tanker vehicle that is fixed or extendable. it is one of the crucial selection criteria since can affect the maneuverability of a tanker vehicle and utility of these kinds of vehicles in all dangerous goods transport operations.

C10 Number of divisions: it means the number of internal baffles in a tanker truck. while it causes to reduce carriage capacity of a vehicle, allows carrying different types of liquid cargo (i.e. oil, diesel, gasoline, and etc.) in a single transport operation.

C11 Design Pressure Value: it refers to technical requirements for loading, unloading liquid cargo in terms of bar or psi. standards for these requirements at a minimum level have determined by international institutions such as UNECE.

C12 Design Temperature Value Max: providing a certain temperature value may be required when special liquid cargoes are carried. Hence, it means the temperature value that can be provided by a road tanker vehicle at a maximum degree.

C13 Design Temperature Value Min: it means the temperature value that can be provided by a road tanker vehicle at a minimum degree.

Next, the decision alternatives were determined together with experts and given in Table 3.

Table 3. Decision alternatives for road tanker vehicles

\begin{tabular}{clcl}
\hline Code & Options & Code & Options \\
\hline $\mathrm{A}_{1}$ & Brand OK. & $\mathrm{A}_{5}$ & Brand KO \\
$\mathrm{A}_{2}$ & Brand OT. & $\mathrm{A}_{6}$ & Brand TR \\
$\mathrm{A}_{3}$ & Brand TA & $\mathrm{A}_{7}$ & Brand RH \\
$\mathrm{A}_{4}$ & Brand TŞ & $\mathrm{A}_{8}$ & Brand IZ \\
\hline
\end{tabular}

While the decision alternatives were determined, road tanker vehicle market of Europe and Turkey was taken into consideration and the products manufactured by key players of the market were included into the scope of the research process. Then, the criteria and options were determined, researchers progressed to the next stage of the proposed fuzzy model.

\subsection{Calculation of the weights of the criteria}

Next, experts performed linguistic evaluations for criteria and alternatives and these evaluations were converted to the corresponding TFNs in the linguistic evaluation scale as given in the Table 4.

Table 4. Linguistic weighting scale for criteria (Perçin, 2019)

\begin{tabular}{lcccc}
\hline & & \multicolumn{3}{c}{ Triangular Fuzzy } \\
\hline Linguistic terms & Abbr. & $l$ & $m$ & $u$ \\
\hline Very Low & VL & 0.00 & 0.00 & 0.30 \\
Low & L & 0.00 & 0.25 & 0.50 \\
Medium & M & 0.30 & 0.50 & 0.70 \\
High & H & 0.50 & 0.75 & 1.00 \\
Very High & VH & 0.70 & 1.00 & 1.00 \\
\hline
\end{tabular}

Step 1. Expert rank the criteria by considering own experiences and judgments. Then the final ranking scores of the criteria were determined by computing the 
Görçün et al./Decis. Mak. Appl. Manag. Eng. 4 (2) (2021) 140-162

geometric mean of ranking scores given by experts for each criterion as shown in Table 5.

Table 5. Ranking of the criteria and the final ranking scores

\begin{tabular}{cccccccc}
\hline Code & DM1 & DM2 & DM3 & DM4 & DM5 & DM6 & Geo Mean \\
\hline $\mathrm{C}_{1}$ & 1 & 2 & 1 & 2 & 2 & 3 & 1.698 \\
$\mathrm{C}_{4}$ & 4 & 5 & 5 & 6 & 5 & 5 & 4.966 \\
$\mathrm{C}_{6}$ & 7 & 6 & 6 & 5 & 7 & 7 & 6.287 \\
$\mathrm{C}_{5}$ & 2 & 3 & 3 & 3 & 3 & 2 & 2.621 \\
$\mathrm{C}_{2}$ & 5 & 4 & 4 & 4 & 1 & 1 & 2.615 \\
$\mathrm{C}_{3}$ & 3 & 1 & 2 & 1 & 4 & 4 & 2.140 \\
$\mathrm{C}_{10}$ & 9 & 10 & 8 & 8 & 9 & 9 & 8.807 \\
$\mathrm{C}_{9}$ & 10 & 9 & 10 & 9 & 10 & 10 & 9.655 \\
$\mathrm{C}_{7}$ & 8 & 8 & 9 & 7 & 8 & 8 & 7.979 \\
$\mathrm{C}_{8}$ & 6 & 7 & 7 & 10 & 6 & 6 & 6.878 \\
$\mathrm{C}_{11}$ & 11 & 11 & 11 & 12 & 11 & 11 & 11.161 \\
$\mathrm{C}_{12}$ & 12 & 13 & 12 & 11 & 12 & 12 & 11.986 \\
$\mathrm{C}_{13}$ & 13 & 12 & 13 & 13 & 13 & 13 & 12.828 \\
\hline
\end{tabular}

Step 2. Experts perform linguistic evaluation for criteria to determine the relative importance ratio of each criterion by making comparison between criterion $j$ and $j-1$ criterion. The determined linguistic evaluations are presented in Table 6.

Table 6. Linguistic evaluations for the relative importance ratios

\begin{tabular}{ccccccc}
\hline Code & DM1 & DM2 & DM3 & DM4 & DM5 & DM6 \\
\hline $\mathrm{C}_{1}$ & - & - & - & - & - & - \\
$\mathrm{C}_{4}$ & VL & VL & VL & L & VL & L \\
$\mathrm{C}_{6}$ & M & H & M & M & M & VL \\
$\mathrm{C}_{5}$ & VL & VL & VL & VL & VL & VL \\
$\mathrm{C}_{2}$ & VL & L & VL & VL & VL & L \\
$\mathrm{C}_{3}$ & VL & M & VL & VL & M & M \\
$\mathrm{C}_{10}$ & H & H & H & VH & L & M \\
$\mathrm{C}_{9}$ & L & VL & L & L & VL & VL \\
$\mathrm{C}_{7}$ & L & VH & M & L & VH & VH \\
$\mathrm{C}_{8}$ & VL & VL & VL & VL & L & L \\
$\mathrm{C}_{11}$ & VH & H & VH & M & VH & VH \\
$\mathrm{C}_{12}$ & VL & L & VL & L & L & L \\
$C_{13}$ & VL & L & VL & L & L & L \\
\hline
\end{tabular}

The weights of the factors were computed and presented in Table 7.

Table 7. The results obtained by applying the fuzzy SWARA technique

\begin{tabular}{|c|c|c|c|c|c|c|c|c|c|c|c|c|c|c|}
\hline Code & & $\tilde{s}_{j}$ & & & $k_{j}$ & & & $q_{j}$ & & & $w_{j}$ & & $\begin{array}{c}d_{\text {fuzzie }} \\
d\end{array}$ & $w_{j}$ \\
\hline $\mathrm{C}_{1}$ & & & & 1.000 & 1.000 & 1.000 & 1.000 & 1.000 & 1.000 & 0.137 & 0.191 & 0.318 & 0.215 & 0.172 \\
\hline $\mathrm{C}_{4}$ & 0.000 & 0.083 & 0.367 & 1.000 & 1.083 & 1.367 & 0.732 & 0.923 & 1.000 & 0.100 & 0.176 & 0.318 & 0.198 & 0.158 \\
\hline $\mathrm{C}_{6}$ & 0.283 & 0.458 & 0.683 & 1.283 & 1.458 & 1.683 & 0.435 & 0.633 & 0.779 & 0.060 & 0.121 & 0.248 & 0.143 & 0.114 \\
\hline $\mathrm{C}_{5}$ & 0.000 & 0.000 & 0.300 & 1.000 & 1.000 & 1.300 & 0.334 & 0.633 & 0.779 & 0.046 & 0.121 & 0.248 & 0.138 & 0.110 \\
\hline $\mathrm{C}_{2}$ & 0.000 & 0.083 & 0.367 & 1.000 & 1.083 & 1.367 & 0.245 & 0.584 & 0.779 & 0.034 & 0.111 & 0.248 & 0.131 & 0.105 \\
\hline $\mathrm{C}_{3}$ & 0.150 & 0.250 & 0.500 & 1.150 & 1.250 & 1.500 & 0.163 & 0.467 & 0.678 & 0.022 & 0.089 & 0.215 & 0.109 & 0.087 \\
\hline $\mathrm{C}_{10}$ & 0.417 & 0.667 & 0.867 & 1.417 & 1.667 & 1.867 & 0.087 & 0.280 & 0.478 & 0.012 & 0.053 & 0.152 & 0.072 & 0.058 \\
\hline $\mathrm{C}_{9}$ & 0.000 & 0.125 & 0.400 & 1.000 & 1.125 & 1.400 & 0.062 & 0.249 & 0.478 & 0.009 & 0.047 & 0.152 & 0.069 & 0.055 \\
\hline $\mathrm{C}_{7}$ & 0.400 & 0.667 & 0.783 & 1.400 & 1.667 & 1.783 & 0.035 & 0.150 & 0.342 & 0.005 & 0.028 & 0.109 & 0.047 & 0.038 \\
\hline
\end{tabular}


Evaluation of tanker vehicle selection using a novel hybrid fuzzy MCDM technique

\begin{tabular}{ccccccccccccccc}
\hline $\mathrm{C}_{8}$ & 0.000 & 0.083 & 0.367 & 1.000 & 1.083 & 1.367 & 0.026 & 0.138 & 0.342 & 0.004 & 0.026 & 0.109 & 0.046 & 0.037 \\
$\mathrm{C}_{11}$ & 0.600 & 0.875 & 0.950 & 1.600 & 1.875 & 1.950 & 0.013 & 0.074 & 0.214 & 0.002 & 0.014 & 0.068 & 0.028 & 0.022 \\
$\mathrm{C}_{12}$ & 0.000 & 0.167 & 0.433 & 1.000 & 1.167 & 1.433 & 0.009 & 0.063 & 0.214 & 0.001 & 0.012 & 0.068 & 0.027 & 0.022 \\
$\mathrm{C}_{13}$ & 0.000 & 0.167 & 0.433 & 1.000 & 1.167 & 1.433 & 0.006 & 0.054 & 0.214 & 0.001 & 0.010 & 0.068 & 0.026 & 0.021 \\
\hline
\end{tabular}

\subsection{Determining the preference ratings of the alternatives}

The example is related to road tanker vehicles used in the field of dangerous goods transportation. Hazardous transportation firms need to assess all potential tanker vehicles and have to choose the appropriate alternative among them to reach safe, effective, and productive transport operations. In order to conduct successful and productive research and reach accurate, reasonable, and realistic results, a board of experts was constructed by researchers, and they took on a task as advisors and experts during the research process as mentioned in the previous section.

Step 1. Experts performed linguistic evaluations for decision alternatives considering the linguistic terms given in Table 8. These evaluations were converted to the corresponding TFNs in the linguistic evaluation scale.

Table 8. Linguistic scale for alternatives (Chen, 2000)

\begin{tabular}{ccccc}
\hline & \multicolumn{4}{c}{ Triangular Fuzzy } \\
\hline Linguistic terms & Abbr. & $\mathrm{l}$ & $\mathrm{m}$ & $\mathrm{u}$ \\
\hline Very Poor & $\mathrm{VP}$ & 0 & 0 & 1 \\
Poor & $\mathrm{P}$ & 0 & 1 & 3 \\
Medium Poor & $\mathrm{MP}$ & 1 & 3 & 5 \\
Medium & $\mathrm{M}$ & 3 & 5 & 7 \\
Medium Good & $\mathrm{MG}$ & 5 & 7 & 9 \\
Good & $\mathrm{G}$ & 7 & 9 & 10 \\
Very Good & $\mathrm{VG}$ & 9 & 10 & 10 \\
\hline
\end{tabular}

After, these evaluations were converted to the TFNs, $k$ number of initial fuzzy decision matrices were generated and these matrices were combined and the aggregated fuzzy matrix (Table 9) was constructed as follows.

Step 2. The fuzzy weight of each criterion was computed by using the F-SWARA technique. The obtained fuzzy weights of the criteria are given in Table 7.

Table 9. The initial fuzzy matrix

\begin{tabular}{|c|c|c|c|c|c|c|c|c|c|c|c|c|c|c|c|}
\hline Code & & $\mathrm{A}_{1}$ & & & $\mathrm{~A}_{2}$ & & & $\mathrm{~A}_{3}$ & & & $\mathrm{~A}_{4}$ & & & $\mathrm{~A}_{5}$ & \\
\hline & $l$ & $m$ & $u$ & $l$ & $m$ & $u$ & $l$ & $m$ & $u$ & $l$ & $m$ & $u$ & $l$ & $m$ & $u$ \\
\hline $\mathrm{C}_{1}$ & 2.57 & 3.71 & 5.14 & 5.14 & 6.86 & 8.14 & 3.86 & 5.29 & 6.57 & 3.00 & 4.57 & 6.29 & 1.43 & 2.71 & 4.43 \\
\hline $\mathrm{C}_{2}$ & 5.57 & 7.14 & 8.14 & 4.57 & 6.14 & 7.57 & 7.00 & 8.43 & 9.14 & 6.29 & 7.57 & 8.43 & 1.71 & 2.86 & 4.43 \\
\hline $\mathrm{C}_{3}$ & 1.57 & 2.43 & 3.86 & 4.14 & 5.43 & 6.71 & 2.29 & 2.86 & 3.86 & 6.00 & 7.57 & 8.57 & 2.57 & 3.71 & 5.14 \\
\hline $\mathrm{C}_{4}$ & 6.57 & 7.86 & 8.57 & 6.14 & 7.71 & 8.71 & 7.00 & 8.43 & 9.29 & 7.57 & 9.14 & 9.86 & 6.43 & 8.14 & 9.14 \\
\hline $\mathrm{C}_{5}$ & 4.86 & 6.29 & 7.57 & 3.71 & 4.71 & 5.86 & 4.00 & 5.71 & 7.29 & 2.57 & 4.29 & 6.00 & 6.86 & 8.29 & 9.00 \\
\hline $\mathrm{C}_{6}$ & 6.14 & 8.00 & 9.14 & 7.29 & 8.86 & 9.57 & 7.57 & 9.00 & 9.57 & 7.00 & 8.71 & 9.57 & 6.71 & 8.43 & 9.43 \\
\hline $\mathrm{C}_{7}$ & 4.43 & 5.71 & 6.86 & 5.57 & 6.86 & 7.86 & 5.14 & 7.00 & 8.43 & 6.43 & 8.00 & 8.86 & 5.86 & 7.57 & 8.86 \\
\hline $\mathrm{C}_{8}$ & 7.29 & 8.86 & 9.57 & 3.57 & 4.86 & 6.00 & 4.86 & 6.43 & 7.71 & 5.57 & 6.86 & 7.71 & 4.29 & 5.86 & 7.43 \\
\hline $\mathrm{C}_{9}$ & 5.14 & 6.57 & 7.71 & 4.43 & 5.71 & 6.86 & 4.86 & 6.43 & 7.71 & 6.00 & 7.57 & 8.57 & 7.00 & 8.71 & 9.71 \\
\hline $\mathrm{C}_{10}$ & 7.86 & 9.29 & 9.86 & 6.29 & 7.71 & 8.71 & 8.14 & 9.57 & 10.00 & 6.43 & 8.29 & 9.43 & 6.86 & 8.29 & 9.00 \\
\hline $\mathrm{C}_{11}$ & 0.71 & 1.14 & 2.43 & 1.14 & 1.86 & 3.29 & 3.00 & 3.57 & 4.43 & 7.86 & 9.14 & 9.57 & 6.71 & 8.43 & 9.43 \\
\hline $\mathrm{C}_{12}$ & 3.29 & 4.71 & 6.14 & 5.14 & 7.00 & 8.43 & 7.57 & 9.14 & 9.86 & 5.14 & 7.00 & 8.43 & 5.57 & 7.43 & 8.86 \\
\hline $\mathrm{C}_{13}$ & 3.57 & 5.14 & 6.86 & 4.86 & 6.71 & 8.14 & 4.86 & 6.43 & 7.86 & 5.86 & 7.43 & 8.57 & 7.29 & 8.86 & 9.71 \\
\hline Code & & $\mathrm{A}_{6}$ & & & $\mathrm{~A}_{7}$ & & & $\mathrm{~A}_{8}$ & & & & & & & \\
\hline
\end{tabular}


Görçün et al./Decis. Mak. Appl. Manag. Eng. 4 (2) (2021) 140-162

\begin{tabular}{lccccccccc}
\hline & $l$ & $m$ & $u$ & $l$ & $m$ & $u$ & $l$ & $m$ & $u$ \\
$\mathrm{C} 1$ & 3.43 & 4.57 & 5.86 & 2.86 & 3.71 & 4.71 & 6.14 & 7.00 & 7.43 \\
$\mathrm{C} 2$ & 1.43 & 2.86 & 4.71 & 5.86 & 6.86 & 7.43 & 5.29 & 6.43 & 7.29 \\
$\mathrm{C} 3$ & 3.57 & 5.29 & 7.00 & 3.57 & 5.14 & 6.57 & 1.71 & 2.14 & 3.14 \\
$\mathrm{C} 4$ & 5.29 & 6.57 & 7.57 & 7.57 & 9.00 & 9.57 & 6.29 & 7.71 & 8.57 \\
$\mathrm{C} 5$ & 6.71 & 8.29 & 9.14 & 7.00 & 8.57 & 9.43 & 4.86 & 6.14 & 7.14 \\
$\mathrm{C} 6$ & 6.43 & 8.14 & 9.14 & 6.71 & 8.43 & 9.43 & 5.71 & 7.14 & 8.14 \\
$\mathrm{C} 7$ & 7.29 & 8.71 & 9.57 & 5.00 & 6.29 & 7.43 & 4.86 & 6.71 & 8.29 \\
$\mathrm{C} 8$ & 2.71 & 4.14 & 5.86 & 3.86 & 5.14 & 6.43 & 3.71 & 5.29 & 6.71 \\
$\mathrm{C} 9$ & 4.71 & 6.00 & 7.14 & 7.00 & 8.57 & 9.43 & 5.14 & 6.57 & 7.71 \\
$\mathrm{C} 10$ & 8.14 & 9.57 & 10.00 & 7.86 & 9.43 & 10.00 & 6.86 & 8.14 & 8.71 \\
$\mathrm{C} 11$ & 5.14 & 5.71 & 6.14 & 3.43 & 4.43 & 5.57 & 4.29 & 5.14 & 6.00 \\
$\mathrm{C} 12$ & 5.14 & 7.00 & 8.43 & 7.29 & 8.86 & 9.57 & 7.43 & 8.43 & 8.71 \\
$\mathrm{C} 13$ & 8.71 & 9.86 & 10.00 & 7.29 & 8.86 & 9.71 & 7.29 & 8.71 & 9.29 \\
\hline
\end{tabular}

Step 3-5. By implementing the equation 8, the initial fuzzy matrix was normalized. Afterward, with the help of equation 9, the matrix was weighted (Table 10) as follows in the step 4. Next, by applying equation 10-11, the fuzzy negative-ideal solutions( $\left.n s_{j}\right)$ were computed.

Table 10. The weighted normalized fuzzy matrix

\begin{tabular}{|c|c|c|c|c|c|c|c|c|c|c|c|c|c|c|c|}
\hline \multirow[t]{2}{*}{ Code } & \multicolumn{3}{|c|}{ A1 } & \multicolumn{3}{|c|}{ A2 } & \multicolumn{4}{|c|}{ A3 } & \multicolumn{2}{|c|}{ A4 } & \multicolumn{3}{|c|}{ A5 } \\
\hline & l & $\mathrm{m}$ & $\mathrm{u}$ & l & $\mathrm{m}$ & $\mathrm{u}$ & l & $\mathrm{m}$ & $\mathrm{u}$ & l & $\mathrm{m}$ & $\mathrm{u}$ & l & $\mathrm{m}$ & $\mathrm{u}$ \\
\hline C1 & 0.07 & 0.12 & 0.24 & 0.03 & 0.06 & 0.15 & 0.05 & 0.09 & 0.20 & 0.05 & 0.10 & 0.22 & 0.08 & 0.14 & 0.27 \\
\hline $\mathrm{C} 2$ & 0.01 & 0.03 & 0.11 & 0.01 & 0.04 & 0.13 & 0.00 & 0.02 & 0.07 & 0.01 & 0.03 & 0.09 & 0.02 & 0.08 & 0.21 \\
\hline C3 & .00 & 02 & 0 . & 01 & 05 & 0. & 0.01 & 0.03 & 0.08 & 0.01 & 0.07 & 0.18 & .01 & 03 & 0.11 \\
\hline $\mathrm{C} 4$ & 0.07 & 0.14 & 0.27 & 0.06 & 0.14 & 0.28 & 0.07 & 0.15 & 0.30 & 0.08 & 0.16 & 0.31 & 0.06 & 0.14 & 0.29 \\
\hline C5 & 0.02 & 0.08 & 0.19 & 0.02 & 0.06 & 0.14 & 0.02 & 0.07 & 0.18 & 0.01 & 0.05 & 0.15 & 0.03 & 0.10 & 0.22 \\
\hline C6 & 0.04 & 0.10 & 0.23 & 0.04 & 0.11 & 0.24 & 0.05 & 0.11 & 0.24 & 0.04 & 0.11 & 0.24 & 0.04 & 0.10 & 0.23 \\
\hline C7 & 0.00 & 0.02 & 0.07 & 0.00 & 0.02 & 0.09 & 0.00 & 0.02 & 0.09 & 0.00 & 0.02 & 0.10 & 0.00 & 0.02 & 0.10 \\
\hline C8 & 0.00 & 0.00 & 0.03 & 0.00 & 0.01 & 0.0 & 0.00 & 0.01 & 0.06 & 0.00 & 0.01 & 0.05 & 0.00 & 0.01 & 0.06 \\
\hline C9 & 0.00 & 0.02 & 0.07 & 0.00 & 0.02 & 0.08 & 0.00 & 0.02 & 0.08 & 0.00 & 0.01 & 0.06 & 0.00 & 0.01 & 0.05 \\
\hline C10 & 0.01 & 0.05 & 0.15 & 0.01 & 0.04 & 0.13 & 0.01 & 0.05 & 0.15 & 0.01 & 0.04 & 0.14 & 0.01 & 0.04 & 0.14 \\
\hline C11 & 0.00 & 0.00 & 0.02 & 0.00 & 0.00 & 0.02 & 0.00 & 0.01 & 0.03 & 0.00 & 0.01 & 0.06 & 0.00 & 0.01 & 0.06 \\
\hline C12 & 0.00 & 0.01 & 0.04 & 0.00 & 0.01 & 0.06 & 0.00 & 0.01 & 0.07 & 0.00 & 0.01 & 0.06 & 0.00 & 0.01 & 0.06 \\
\hline C13 & 0.00 & 0.01 & 0.04 & 0.00 & 0.00 & 0.03 & 0.00 & 0.00 & 0.03 & 0.00 & 0.00 & 0.03 & 0.00 & 0.00 & 0.02 \\
\hline
\end{tabular}

Table 10. The weighted normalized fuzzy matrix (Continue)

\begin{tabular}{ccccccccccccc}
\hline Code & \multicolumn{3}{c}{$\mathrm{A}_{6}$} & \multicolumn{1}{c}{$\mathrm{A}_{7}$} & \multicolumn{3}{c}{$\mathrm{A}_{8}$} & \multicolumn{3}{c}{$n s_{j}$} \\
\cline { 2 - 14 } & $l$ & $m$ & $u$ & $l$ & $m$ & $u$ & $l$ & $m$ & $u$ & $l$ & $m$ & $u$ \\
\cline { 2 - 14 } $\mathrm{C}_{1}$ & 0.06 & 0.10 & 0.21 & 0.07 & 0.12 & 0.23 & 0.04 & 0.06 & 0.12 & 0.025 & 0.057 & 0.123 \\
$\mathrm{C}_{2}$ & 0.02 & 0.08 & 0.21 & 0.01 & 0.03 & 0.10 & 0.01 & 0.04 & 0.12 & 0.003 & 0.017 & 0.074 \\
$\mathrm{C}_{3}$ & 0.01 & 0.05 & 0.15 & 0.01 & 0.05 & 0.14 & 0.00 & 0.02 & 0.07 & 0.004 & 0.019 & 0.068 \\
$\mathrm{C}_{4}$ & 0.05 & 0.12 & 0.24 & 0.08 & 0.16 & 0.30 & 0.06 & 0.14 & 0.27 & 0.053 & 0.116 & 0.241 \\
$\mathrm{C}_{5}$ & 0.03 & 0.10 & 0.23 & 0.03 & 0.10 & 0.23 & 0.02 & 0.07 & 0.18 & 0.012 & 0.052 & 0.145 \\
$\mathrm{C}_{6}$ & 0.04 & 0.10 & 0.23 & 0.04 & 0.10 & 0.23 & 0.03 & 0.09 & 0.20 & 0.034 & 0.086 & 0.202 \\
$\mathrm{C}_{7}$ & 0.00 & 0.02 & 0.10 & 0.00 & 0.02 & 0.08 & 0.00 & 0.02 & 0.09 & 0.002 & 0.016 & 0.074 \\
$\mathrm{C}_{8}$ & 0.00 & 0.02 & 0.08 & 0.00 & 0.01 & 0.07 & 0.00 & 0.01 & 0.07 & 0.000 & 0.003 & 0.029 \\
$\mathrm{C}_{9}$ & 0.00 & 0.02 & 0.08 & 0.00 & 0.01 & 0.05 & 0.00 & 0.02 & 0.07 & 0.000 & 0.006 & 0.046 \\
$\mathrm{C}_{10}$ & 0.01 & 0.05 & 0.15 & 0.01 & 0.05 & 0.15 & 0.01 & 0.04 & 0.13 & 0.008 & 0.041 & 0.132 \\
$\mathrm{C}_{11}$ & 0.00 & 0.01 & 0.04 & 0.00 & 0.01 & 0.04 & 0.00 & 0.01 & 0.04 & 0.000 & 0.002 & 0.016 \\
\hline
\end{tabular}


Evaluation of tanker vehicle selection using a novel hybrid fuzzy MCDM technique

\begin{tabular}{lllllllllllll}
\hline $\mathrm{C}_{12}$ & 0.00 & 0.01 & 0.06 & 0.00 & 0.01 & 0.06 & 0.00 & 0.01 & 0.06 & 0.000 & 0.006 & 0.042 \\
$\mathrm{C}_{13}$ & 0.00 & 0.00 & 0.01 & 0.00 & 0.00 & 0.02 & 0.00 & 0.00 & 0.02 & 0.000 & 0.000 & 0.009 \\
\hline
\end{tabular}

Step 6. The Euclidean distance $\left(\mathrm{ED}_{\mathrm{i}}\right)$ and Hamming distance $\left(\mathrm{HD}_{\mathrm{i}}\right)$ were calculated by using equations 12 and 13 . The computed values are presented in Table 11.

Table 11. The Euclidean distance $\left(E D_{i}\right)$ and Hamming distance $\left(H D_{i}\right)$ for each option

\begin{tabular}{ccccccccc}
\hline Code & $\mathrm{A}_{1}$ & $\mathrm{~A}_{2}$ & $\mathrm{~A}_{3}$ & $\mathrm{~A}_{4}$ & $\mathrm{~A}_{5}$ & $\mathrm{~A}_{6}$ & $\mathrm{~A}_{7}$ & $\mathrm{~A}_{8}$ \\
\hline $\mathrm{ED}_{\mathrm{i}}$ & 0.213 & 0.408 & 0.223 & 0.294 & 0.376 & 0.349 & 0.320 & 0.150 \\
$\mathrm{HD}_{\mathrm{i}}$ & 0.184 & 0.173 & 0.187 & 0.245 & 0.322 & 0.292 & 0.279 & 0.121 \\
\hline
\end{tabular}

Step 7. The relative assessment matrix was constructed by applying equation 14 15. The threshold parameter $(\theta)$ was taken as 0.02 in the current paper.

Step 8 . The assessment score $\left(A S_{i}\right)$ of each alternative was calculated by using equation 16 . The relative assessment matrix and the assessment scores of options are presented in Table 12.

Table 12. The relative assessment matrix and the assessment scores of options

\begin{tabular}{ccccccccccc}
\hline Code & $\mathrm{A}_{1}$ & $\mathrm{~A}_{2}$ & $\mathrm{~A}_{3}$ & $\mathrm{~A}_{4}$ & $\mathrm{~A}_{5}$ & $\mathrm{~A}_{6}$ & $\mathrm{~A}_{7}$ & $\mathrm{~A}_{8}$ & $A S_{i}$ & Rank \\
\hline $\mathrm{A}_{1}$ & 0.00 & -0.18 & -0.01 & -0.14 & -0.30 & -0.24 & -0.20 & 0.13 & -0.95 & 7 \\
$\mathrm{~A}_{2}$ & 0.18 & 0.00 & 0.17 & 0.04 & -0.12 & -0.06 & -0.02 & 0.31 & 0.52 & 4 \\
$\mathrm{~A}_{3}$ & 0.01 & -0.17 & 0.00 & -0.13 & -0.29 & -0.23 & -0.19 & 0.14 & -0.86 & 6 \\
$\mathrm{~A}_{4}$ & 0.14 & -0.04 & 0.13 & 0.00 & -0.16 & -0.10 & -0.06 & 0.27 & 0.17 & 5 \\
$\mathrm{~A}_{5}$ & 0.30 & 0.12 & 0.29 & 0.16 & 0.00 & 0.06 & 0.10 & 0.43 & 1.45 & 1 \\
$\mathrm{~A}_{6}$ & 0.24 & 0.06 & 0.23 & 0.10 & -0.06 & 0.00 & 0.04 & 0.37 & 0.99 & 2 \\
$\mathrm{~A}_{7}$ & 0.20 & 0.02 & 0.19 & 0.06 & -0.10 & -0.04 & 0.00 & 0.33 & 0.65 & 3 \\
$\mathrm{~A}_{8}$ & -0.13 & -0.31 & -0.14 & -0.27 & -0.43 & -0.37 & -0.33 & 0.00 & -1.97 & 8 \\
\hline
\end{tabular}

Step 9. At the end of the F-CODAS technique, the decision alternatives were ranked with respect to their assessment scores.

\section{The Validation Test}

A comprehensive sensitivity analysis consisting of two stages was performed to test the validation of the proposed integrated novel fuzzy model. First, impact of changing the weights of the input and output factors on the ranking results were examined. Secondly, the results of the proposed model were compared to the results of different fuzzy techniques.

a) Examination of impacts of changing the weights of the criteria on the ranking performances of the alternatives: In the first stage of the sensitivity analysis, the weight of each criterion is modified to examine its impacts on the preference ratings of the option by forming 130 scenarios. Previous works suggested changing the weights of criteria that are in the first three ranks (Stankovic et al., 2020). This kind of approach can give a limited result since it did not consider the potential impacts of changes in weights of the remained criteria. This work takes into consideration the potential effects of all criteria having impacts on the results more or less. therefore, While the weight of each factor is modified at the rate of $10 \%$ in each scenario, the weights of the remaining factors are corrected to meet the condition of the sum of 
weights should be equal to 1 . New weight values of the criteria are determined for each scenario with the help of equations 17,18 , and 19 respectively.

$w_{n v}^{1}=w_{p v}^{1}-\left(w_{p v}^{1} \cdot \zeta_{v}\right)$

$w_{r f v}^{2}=\frac{\left(1-w_{n v}^{1}\right)}{n-1}+w_{p v}^{2}$

$w_{n v}^{1}+\sum w_{r f v}^{2}=1$

Here, $w_{n v}^{1}$ denotes new value of modified weight of $j^{\text {th }}$ factor, $w_{p v}^{1}$ is the previous values of the criterion, $\zeta_{v}$ is the modification degree in terms of percentage (i.e. $10 \%$, $20 \%, \ldots, 100 \%)$. Also, $w_{1 r f v}^{2}$ symbolizes new values of remaining factors, $n$ is the number of factors, $w_{p v}^{2}$ is the previous values of the remaining criteria.

To examine the effects of modified weights on the preference ratings of the options, the new ranking performances of the alternatives are calculated by using the changed new weights of the criteria and the obtained results are presented in Figure 2.

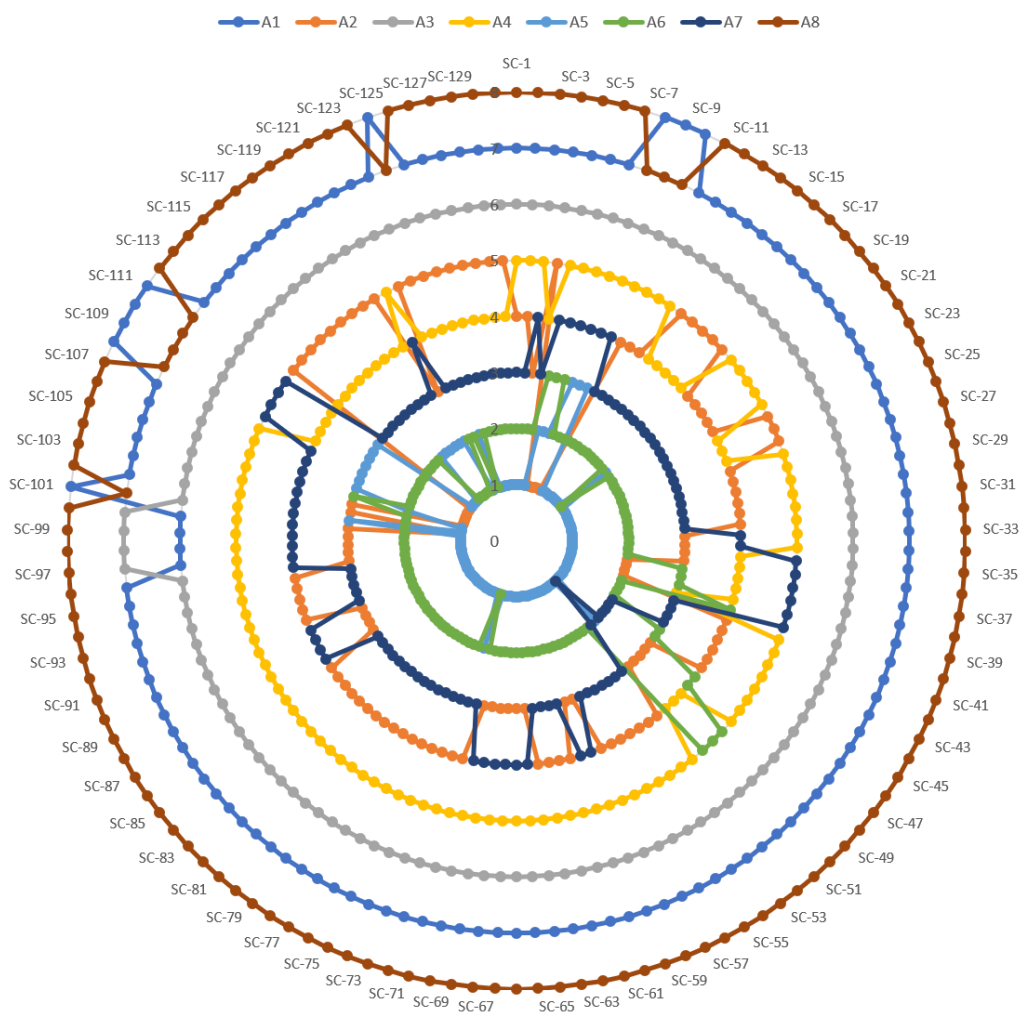

Figure 2. Impacts of changes of criteria weight on the ranking performance of the alternatives 


\section{Evaluation of tanker vehicle selection using a novel hybrid fuzzy MCDM technique}

When impacts of modification of the criteria weight on preference ratings of the options are evaluated, the same ranking result has been obtained for 51 scenarios and average correlation coefficient value among the results of the scenarios has been determined as $95.67 \%$ for all scenarios. A5 has remained as the best option for 105 scenarios $(80.77 \%)$. When the weight value of criterion 1 th is changed at the rate of $50 \%$, the ranking position of $\mathrm{A} 5$ has also changed. In addition, it has been observed the same situation, when the weights of the criteria C11 (at over 40\%) and C12 (at over $60 \%$ ) has been changed.

A6 which has been determined as the second-best alternative by applying the proposed fuzzy model has also remained at the same ranking position for 106 scenarios (81.54\%). The ranking performance of A3 has changed for only 4 scenarios, and it has remained at the same rank for 126 scenarios (90\%). Changes in preference ratings of other alternatives are presented in the following Table13.

Table 13. Ranking of the options with respect to 130 scenarios

\begin{tabular}{cccccccccc}
\hline Code & $1^{\text {th }}$ & $2^{\text {th }}$ & $3^{\text {th }}$ & $4^{\text {th }}$ & $5^{\text {th }}$ & $6^{\text {th }}$ & $7^{\text {th }}$ & $8^{\text {th }}$ & Similarity (\%) \\
\hline $\mathrm{A}_{1}$ & 0 & 0 & 0 & 0 & 0 & 4 & 117 & 9 & 90.00 \\
$\mathrm{~A}_{2}$ & 15 & 4 & 30 & 54 & 27 & 0 & 0 & 0 & 41.54 \\
$\mathrm{~A}_{3}$ & 0 & 0 & 0 & 0 & 0 & 126 & 4 & 0 & 96.92 \\
$\mathrm{~A}_{4}$ & 0 & 0 & 1 & 39 & 90 & 0 & 0 & 0 & 69.23 \\
$\mathrm{~A}_{5}$ & 105 & 14 & 11 & 0 & 0 & 0 & 0 & 0 & 80.77 \\
$\mathrm{~A}_{6}$ & 9 & 106 & 9 & 3 & 3 & 0 & 0 & 0 & 81.54 \\
$\mathrm{~A}_{7}$ & 1 & 6 & 79 & 34 & 10 & 0 & 0 & 0 & 60.77 \\
$\mathrm{~A}_{8}$ & 0 & 0 & 0 & 0 & 0 & 0 & 9 & 121 & 93.08 \\
\hline
\end{tabular}

When the results of the first stage of the sensitivity analysis are evaluated in general, slight changes which cannot change the overall results in the preference ratings of the alternatives depending on modification of the weight values of the criteria. These changes occur when the weights of the criteria were changed. Although modifications were made in the weights of criteria at excessive level, the obtained results show that the proposed integrated fuzzy approach is a very strong technique giving accurate, realistic and reasonable results even in adverse conditions which have low possibility of emergence.

b) Making Comparisons with other fuzzy Approaches: In this stage, the results of the proposed fuzzy model is compared with fuzzy approaches such as F-MABAC (Jokić et al., 2021), F-EDAS (Keshavarz-Ghorabaee et al., 2016b), F-MARCOS (Stanković et al., 2020), F-TOPSIS (Chen et al., 2000), and F-MAIRCA (Boral et al., 2020). The obtained results of the comparisons is shown in Figure 4. 


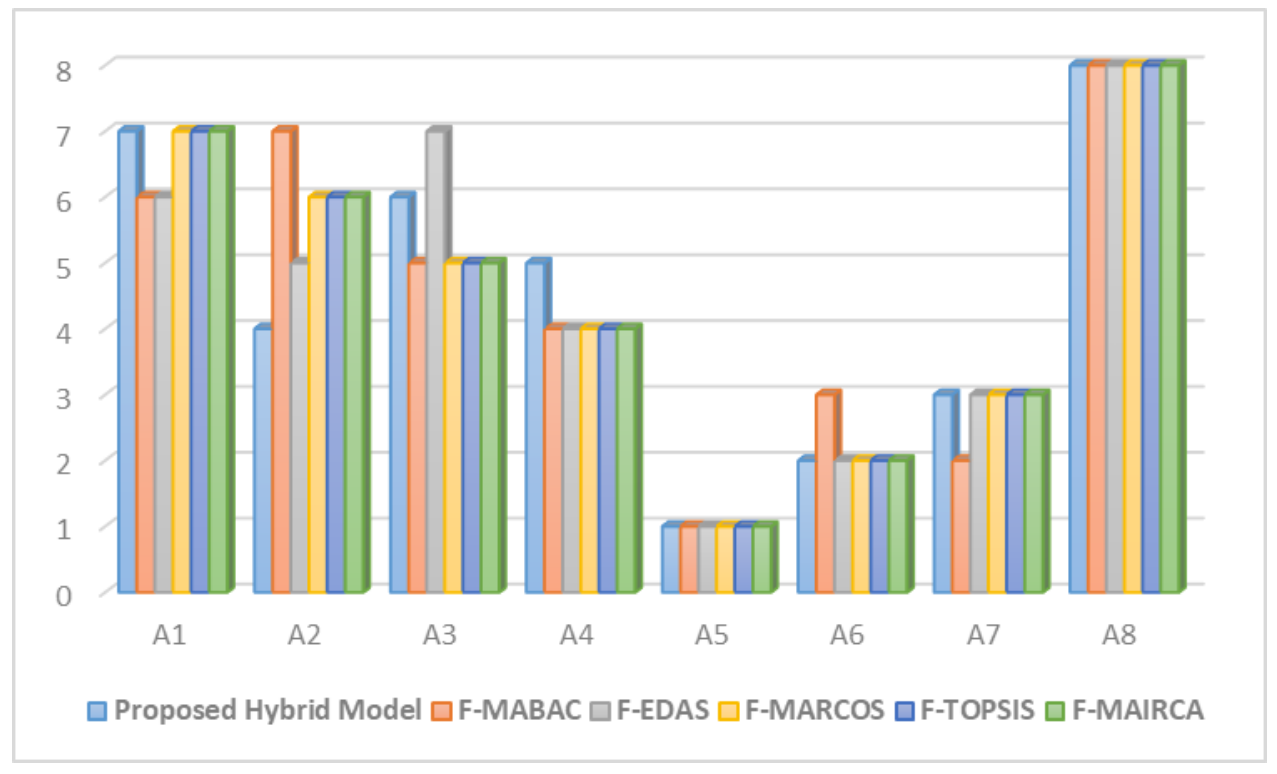

Figure 4. Re-ranking of the decision alternatives with respect implemented other fuzzy decision models.

It is observed that A5 determined as the best option by using the proposed fuzzy approach is also the best alternative for all applied fuzzy techniques. A6 which is the second-best alternative and A7 that is the third-best option have remained in the same rank for all implemented fuzzy techniques except the fuzzy MABAC. Also, the ranking position of $\mathrm{A} 8$ has not changed for all applied fuzzy approaches. It has been observed that there are slight changes in ranking performances of remained alternatives. The Spearman correlation coefficients between the proposed model and other fuzzy MCDM techniques were calculated and the obtained results are given in Table 14.

Table 14. Spearman's correlation (SSC) coefficients among the fuzzy MCDM methods

\begin{tabular}{lcccccc}
\hline \multicolumn{1}{c}{ Code } & $\begin{array}{c}\text { Proposed Hybrid } \\
\text { Model }\end{array}$ & $\begin{array}{c}\text { Fuzzy- } \\
\text { MABAC }\end{array}$ & $\begin{array}{c}\text { Fuzzy- } \\
\text { EDAS }\end{array}$ & $\begin{array}{c}\text { Fuzzy- } \\
\text { MARCOS }\end{array}$ & $\begin{array}{c}\text { Fuzzy- } \\
\text { TOPSIS }\end{array}$ & $\begin{array}{c}\text { Fuzzy- } \\
\text { MAIRCA }\end{array}$ \\
\hline Proposed Hybrid & 1 &, $833^{*}$ &, $952^{* *}$ &, $929^{* *}$ &, $929^{* *}$ &, $929^{* *}$ \\
Model &, $833^{*}$ & 1 &, $881^{* *}$ &, $952^{* *}$ &, $952^{* *}$ &, $952^{* *}$ \\
Fuzzy-MABAC &, $952^{* *}$ &, $881^{* *}$ & 1 &, $929^{* *}$ &, $929^{* *}$ &, $929^{* *}$ \\
Fuzzy-EDAS &, $929^{* *}$ &, $952^{* *}$ &, $929^{* *}$ & 1 & $1,000^{* *}$ & $1,000^{* *}$ \\
Fuzzy-MARCOS &, $929^{* *}$ &, $952^{* *}$ &, $929^{* *}$ & $1,000^{* *}$ & 1 & $1,000^{* *}$ \\
Fuzzy-TOPSIS &, $929^{* *}$ &, $952^{* *}$ &, $929^{* *}$ & $1,000^{* *}$ & $1,000^{* *}$ & 1 \\
Fuzzy-MAIRCA & * Correlation is significant at the 0.05 level (2-tailed). & & & & \\
** Correlation is significant at the 0.01 level (2-tailed). &
\end{tabular}

Since the average correlation value is high at the rate of 0.914 , the results of the sensitivity analysis validate the proposed model. 
Evaluation of tanker vehicle selection using a novel hybrid fuzzy MCDM technique

\section{Overall Results and Conclusion}

Dangerous goods transportation is one of the special types of logistics activities requiring a set of special implementations for reducing the risks. Since there is no tolerance to any mistake, each process related to transport operations should be planned. Road tanker vehicle selection is also one of the very crucial decision-making problem since it can affect almost all process related to dangerous goods transportation. The number of studies is limited and there are serious gaps in the literature. There is no mathematical and systematic model applied to solve these kinds of decision-making problems encountered in the field of dangerous goods logistics. Decision-makers make decisions considering their own experiences and individual judgments and they consider almost all selection process as a special case and try to produce solution for each problem individually.

This work proposes a hybrid fuzzy approach that can be applied as a methodological and systematic frame for both scientific works carried out in the future and practitioners who responsible to decide in the field of dangerous goods logistics. The proposed integrated fuzzy technique consists of the SWARA and the CODAS technique and while the F-SWARA is applied to calculate the weights of the criteria, the F-CODAS method is implemented for determining the preference ratings of the decision alternatives.

The proposed integrated fuzzy approach is a novel hybrid technique and it has many advantages compared to traditional MCDM methods. The extended CODAS technique with the help of fuzzy set theory can provide more reasonable, applicable, and accurate results, which appropriate to real life as it uses the Euclidean distance and the Hamming distance, and utilizes only the negative-ideal solution in the evaluation process (Yalçın \& Pehlivan, 2019).

The sensitivity analysis performed to validate the proposed model and its results have verified the applicability of the model. According to the obtained results, as well as the hybrid fuzzy technique can be applied to solve these kinds of decision-making problems, the results obtained by implementing the integrated fuzzy technique proposed in the current paper are accurate, realistic and reasonable. Consequently, the potential contributions of the paper can be summarized as follows:

- The current paper suggests a novel integrated fuzzy approach having an applicable basic algorithm that can also be implemented by decisionmakers who are in the field of logistics industry.

- It presents a methodological frame which can enable to deal with many ambiguities existing in an assessment process on the tanker vehicle selection.

- It determines a set of novel criteria, which can be considered by practitioners in an assessment processes on the selection of appropriate road tanker vehicles.

- It can deal with ambiguities existing in an evaluation process.

- The proposed hybrid approach provides flexibility to the decision-makers

- It can also be applied to solve decision-making problems encountered in various fields.

When the main findings of the paper focusing on the selection of road oil tankers are examined, C1 "Purchasing Price" has been determined as the most significant criterion. C4 "Capacity" and C6 "Safety" criteria follow the first ranked criterion respectively. The importance and sequence of the criteria are aligned from most critical to least critical is $\mathrm{C} 1>\mathrm{C} 4>\mathrm{C} 6>\mathrm{C} 5>\mathrm{C} 2>\mathrm{C} 3>\mathrm{C} 10>\mathrm{C} 9>\mathrm{C} 7>\mathrm{C} 8>\mathrm{C} 11>\mathrm{C} 12>\mathrm{C} 13$. 
According to the results of the analysis, A5 Brand KO is the best alternative that has the highest performance score, and A6 Brand TR and A7 Brand RH follow it. Other options are ranked as follows: $\mathrm{A} 2>\mathrm{A} 4>\mathrm{A} 3>\mathrm{A} 1>\mathrm{A} 8$.

The current work has also some limitations. First of all, experts should be selected carefully to obtain reasonable and realistic results. Therefore, selecting experts who are highly experienced, having deep knowledge, and certificated by authority may beneficial for researchers who will carry out research on this issue in the future. Also, selecting the right and appropriate criteria is crucial, and performing only a literature review for determining the criteria may not be sufficient hence fieldwork performed together with experts may a beneficial way to describe the proper selection criteria.

In addition, the F-CODAS technique can be extended with the help of different operators such as the normalized weighted and normalized weighted geometric Bonferroni aggregate functions (Ecer \& Pamucar, 2020), Heronian mean (HM) operators (Yu et al., 2012), hybrid weight Power Heronian operator (WPHAp,q) and hybrid weight geometric Power Heronian operator (WGPHA p,q) (Pamucar \& Jankovic., 2020). Also, it can be examined comparatively with different approaches based on different IVIF sets such as F-CODAS-SORT, interval-valued intuitionistic trapezoidal fuzzy and Pythagorean fuzzy sets.

Author Contributions: Conceptualization, Ö. F. Görçün; methodology, Ö. F. Görçün, H. Küçükönder, and S. Senthil; validation, H. Küçükönder Ö. F. Görçün, formal analysis, H. Küçükönder, Ö. F. Görçün, and S. Senthil; writing-original draft preparation, Ö. F. Görçün; writing-review and editing, Ö. F. Görçün, S. Senthil, H.Küçükönder.

Funding: This research received no external funding.

Acknowledgments: We appreciate to contributions of all members of the board of experts for they worked devotedly as advisors and experts in the research process.

Conflicts of Interest: there are no conflicts of interest in the current paper.

\section{References}

Ali, Z., Mahmood, T., Ullah, K., \& Khan, Q. (2021). Einstein Geometric Aggregation Operators using a Novel Complex Interval-valued Pythagorean Fuzzy Setting with Application in Green Supplier Chain Management. Reports in Mechanical Engineering, 2(1), 105-134. https://doi.org/10.31181/rme2001020105t.

Alosta, A., Elmansuri, O., \& Badi, I. (2021). Resolving a location selection problem by means of an integrated AHP-RAFSI approach. Reports in Mechanical Engineering, 2(1), 135-142. https://doi.org/10.31181/rme200102135a.

Bęczkowska, S. (2019). The method of optimal route selection in road transport of dangerous goods. Transportation Research Procedia, 40, 1252-1259.

Boral, S., Howard, I., Chaturvedi, S. K., McKee, K. \& Naikan,V.N.A (2020). An integrated approach for fuzzy failure modes and effects analysis using fuzzy AHP and fuzzy MAIRCA. Engineering Failure Analysis, 108, 104195.

Chen, C. T. (2000). Extensions of the TOPSIS for group decision-making under fuzzy environment. Fuzzy Sets and Systems, 114(1), 1-9. 
Evaluation of tanker vehicle selection using a novel hybrid fuzzy MCDM technique

Dahooie, J. H., Vanaki, A. S. \& Mohammadi, N. (2020). Choosing the appropriate system for cloud computing implementation by using the Interval-Valued Intuitionistic Fuzzy CODAS multiattribute decision-making method (Case Study: Faculty of New Sciences and Technologies of Tehran University)," in IEEE Transactions on Engineering Management, 67(3), 855-868.

Deveci, K., Cin, R. \& Kağızman, A. (2020). A modified interval valued intuitionistic fuzzy CODAS method and its application to multi-criteria selection among renewable energy alternatives in Turkey. Applied Soft Computing, 96, 106660.

Deveci, M., Özcan, E., John, R., Covrig, C.-F. \& Pamucar, D. (2020). A Study on Offshore Wind Farm Siting Criteria Using a Novel Interval-valued Fuzzy-rough based Delphi Method. Journal of Environmental Management, 270, 110916.

Ecer, F., \& Pamucar, D. (2020). Sustainable supplier selection: A novel integrated fuzzy best worst method (F-BWM) and fuzzy CoCoSo with Bonferroni (CoCoSo'B) multicriteria model. Journal of Cleaner Production, 266, 121981.

Galieriková, A., Sosedová, J., Dávid, A. \& Bariak, M. (2018). Transport of dangerous goods by rail. MATEC Web of Conferences, 2018, 235, 00004.

Görçün, Ö. F. (2019). Ağır treylerlerin seçiminin AHP yöntemi ile değerlendirilmesi. Düzce Üniversitesi Bilim ve Teknoloji Dergisi, 7 (1), 383-398.

Görçün, Ö. F. (2019a). Karayolu yük taşımacılığında kullanılan standart treyler seçimine etki eden faktörlerin Analitik Hiyerarşi Prosesi ve TOPSIS yöntemleri ile değerlendirilmesi. Anemon Muş Alparslan Üniversitesi Sosyal Bilimler Dergisi, 7 (4), 23-34.

Gul, M., Guneri, A.F. \& Nasirli, S.M. (2019). A fuzzy-based model for risk assessment of routes in oil transportation. International Journal of Environmental Science and Technology, 16, 4671-4686.

Hervás-Peralta, M., Poveda-Reyes, S., Santarremigia, F. E. Molero, G. D. (2020). Designing the layout of terminals with dangerous goods for safer and more secure ports and hinterlands. Case Studies on Transport Policy, 8(2), 300-310.

Huang, S. H. S., Hsu, W. K., Kevin, K., \& Chen, J. W. (2020). A safety evaluation system based on a revised fuzzy AHP for dangerous goods in airfreights. Journal of Transportation Safety \& Security, 12(5), 611-627.

Huang, W., Zhang, Y., Yu, Y., Xu, Y., Xu, M., Zhang, R., De Dieu, G. J., Yin, D. \& Liu, Z. (2021). Historical data-driven risk assessment of railway dangerous goods transportation system: Comparisons between Entropy Weight Method and Scatter Degree Method. Reliability Engineering \& System Safety, 205, 107236.

Jassbi, J. \& Makvandi, P. (2010). Route selection based on soft MODM framework in transportation of hazardous materials. Applied Mathematical Sciences, 63(4), 3121 3132.

Jokić, Ž., Božanić, D., \& Pamučar, D. (2021). Selection of fire position of mortar units using LBWA and Fuzzy MABAC model. Operational Research in Engineering Sciences: Theory and Applications, 4(1), 115-135. https://doi.org/10.31181/oresta20401156j 
Kanj H. \& Abi-Char, P. E. (2019). A new Fuzzy-TOPSIS based risk decision making framework for dangerous good transportation. 2019 IEEE 21st International Conference on High Performance Computing and Communications; IEEE 17th International Conference on Smart City; IEEE 5th International Conference on Data Science and Systems (HPCC/SmartCity/DSS), Zhangjiajie, China, 2019, 2666-2672.

Katranci, A., \& Kundakci, N. (2020). Bulanık CODAS yöntemi ile kripto para yatirim alternatiflerinin değerlendirilmesi. Afyon Kocatepe Üniversitesi Sosyal Bilimler Dergisi, 22(4), 958-973.

Keršuliene, V., Zavadskas, E. K. \& Turskis, Z. (2010) Selection of rational dispute resolution method by applying new step-wise weight assessment ratio analysis (Swara), Journal of Business Economics and Management, 11(2), 243-258, https://doi.org/10.3846/jbem.2010.12.

Keshavarz Ghorabaee, M., Zavadskas, E. K., Turskis, Z. \& Antucheviciene, J. (2016a). A new combinative distance-based assessment (CODAS) method for multi-criteria decision-making. Economic Computation \& Economic Cybernetics Studies \& Research, 50(3), 25-44.

Keshavarz-Ghorabaee, M., Zavadskas, E., Amiri, M., \& Turskis, Z. (2016b). Extended EDAS Method for Fuzzy Multi-criteria Decision-making: An Application to Supplier Selection. International Journal of Computers Communications \& Control. 11. 358371. 10.15837/ijccc.2016.3.2557.

Li, J. (2018). Multi-Objective Path Selection for Road Transportation of Dangerous Goods, 2018 IEEE 4th International Conference on Control Science and Systems Engineering (ICCSSE), 412-416, https://doi.org/doi: 10.1109/CCSSE.2018.8724681.

Mardani, A., Nilashi, M., Zakuan, N., Loganathan, N., Soheilirad, S., Saman, M.Z.M. \& Ibrahim, O. (2017). A systematic review and meta-Analysis of SWARA and WASPAS methods: Theory and applications with recent fuzzy developments. Applied Soft Computing, 57, 265-292.

Mavi, R.K., Goh, M. \& Zarbakhshnia, N. (2017). Sustainable third-party reverse logistic provider selection with fuzzy SWARA and fuzzy MOORA in plastic industry. The International Journal of Advanced Manufacturing Technology, 91, 2401-2418.

Milosevic, T., Pamucar, D., Chatterjee, P. (2021). Model for selecting a route for the transport of hazardous materials using a fuzzy logic system. Military Technical Courier, 69(2), 355-390.

OECD. (2021). https://data.oecd.org/transport/passenger-car-registrations.htm Accessed 10 April 2021.

Ouhibi, A. \& Frikha, H. M. (2020). Evaluating environmental quality in Tunisia using Fuzzy CODAS SORT method, 2020 International Conference on Decision Aid Sciences and Application (DASA), Sakheer, Bahrain, 1115-1119.

Pamucar, D. \& Ecer, F. (2020). Prioritizing the weights of the evaluation criteria under fuzziness: The fuzzy full consistency method - FUCOM-F. Facta Universitatis, series: Mechanical Engineering. 18(3), 419-437.

Pamučar, D. \& Janković, A. (2020). The application of the hybrid interval rough weighted Power-Heronian operator in multi-criteria decision making. Operational Research in Engineering Sciences: Theory and Applications, 3(2), 54-73. 
Evaluation of tanker vehicle selection using a novel hybrid fuzzy MCDM technique

Pamučar, D. Ljubojević, S. Kostadinović, D. \& Đorović, B. (2016). Cost and risk aggregation in multi-objective route planning for hazardous materials transportation-a neuro-fuzzy and artificial bee colony approach. Expert Systems with Applications, 65, 1-15.

Pamučar, D., Sremac, S., Stević, Ž., Ćirović, G. \& Tomić, D. (2019). New multi-criteria LNN WASPAS model for evaluating the work of advisors in the transport of hazardous goods. Neural Computing and Applications, 31, 1-24.

Pamucar, D.S., \& Savin, L.M. (2020). Multiple-criteria model for optimal off-road vehicle selection for passenger transportation: BWM-COPRAS model. Military Technical Courier, 68(1), 28-64.

Perçin, S. (2019). An integrated fuzzy SWARA and fuzzy AD approach for outsourcing provider selection. Journal of Manufacturing Technology Management, 30(2), 531552.

Petrovic, G., Mihajlovic, J., Cojbasic, Z., Madic, M., \& Marinkovic, D. (2019). Comparison of three fuzzy MCDM methods for solving the supplier selection problem. Facta Universitatis, Series: Mechanical Engineering, 17(3), 455-469.

Raemdonck, K. V., Macharis, C., \& Mairesse, O. (2013). Risk analysis system for the transport of hazardous materials. Journal of Safety Research, 45, 55-63, https://doi.org/10.1016/j.jsr.2013.01.002.

Roy, J., Das, S., Kar, S. \& Pamučar, D. (2019). An Extension of the CODAS approach using interval-valued intuitionistic fuzzy set for sustainable material selection in construction projects with incomplete weight information. Symmetry, 2019; 11(3), 393.

Samanlioglu, F. (2013). A multi-objective mathematical model for the industrial hazardous waste location-routing problem. European Journal of Operational Research, 226(2), 332-340.

Santarremigia, F. E., Molero, G. D., Poveda-Reyes, S. \& Aguilar-Herrando, J. (2018), Railway safety by designing the layout of inland terminals with dangerous goods connected with the rail transport system. Safety Science, 110(Part B), 206-216.

Simic, V., Karagoz, S., Deveci, M. \& Aydin, N. (2021). Picture fuzzy extension of the CODAS method for multi-criteria vehicle shredding facility location. Expert Systems with Applications, 175, 114644.

Stanković, M, Stević, Ž, Das, D.K., Subotić, M., \& Pamučar, D. (2020). A New Fuzzy MARCOS Method for Road Traffic Risk Analysis. Mathematics, 8 (3), 457. https://doi.org/10.3390/math8030457.

Stanković, M., Stević, Ž., Das, D.K., Subotić, M. \& Pamučar, D. (2020). A new fuzzy MARCOS method for road traffic risk analysis. Mathematics, 2020; 8(3), 457.

Sumrit, D., Anuntavoranich, P. \& Vadhanasindhu, P. (2012). Strategic decision for the external technological innovation acquisition mode selection by using an integration of AHP and GRA methods: a case study on a Thai new technology-based firm. IOSR Journal of Business and Management, 6(1), 29-38. 
Görçün et al./Decis. Mak. Appl. Manag. Eng. 4 (2) (2021) 140-162

Vinodh, S., \& Wankhede, V.A. (2020), Application of fuzzy DEMATEL and fuzzy CODAS for analysis of workforce attributes pertaining to Industry 4.0: a case study, International Journal of Quality \& Reliability Management, https://doi.org/10.1108/IJQRM-09-2020-0322.

Wang, P., Wang, J., Wei, G., Wu, J., Wei, C. \& Wei, Y. (2020). CODAS method for multiple attribute group decision making under 2-Tuple linguistic neutrosophic environment. Informatica, 31(1), 161-184.

Yalçın, N., \& Pehlivan, N. (2019). Application of the Fuzzy CODAS Method Based on Fuzzy Envelopes for Hesitant Fuzzy Linguistic Term Sets: A Case Study on a Personnel Selection Problem. Symmetry, 11(4), 493, 1-27.

Yu, D.J., Wu, Y.Y. \& Lu, T. (2012). Interval-valued intuitionistic fuzzy prioritized operators and their application in group decision making. Knowledge-Based Systems, $30,57-66$.

Zadeh, L.A. (1965). Fuzzy Sets. Information and Control, 8(3), 338-353.

Zolfani, S.H. \& Saparauskas, J. (2013). New application of SWARA method in prioritizing sustainability assessment indicators of energy system, Engineering Economics, 24(5), 408-414.

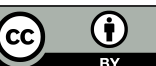

(C) 2018 by the authors. Submitted for possible open access publication under the terms and conditions of the Creative Commons Attribution (CC BY) license (http://creativecommons.org/licenses/by/4.0/). 